m30.p05

\section{Effects of alloying on magnetocaloric characteristics of $\mathrm{Gd5}(\mathrm{Si} 2 \mathrm{Ge} 2)$}

\section{Yalcin Elereman, Atila Yucel, Seda Aksoy}

Department of Engineering Physics, Faculty of Engineering, University of Ankara, 06100 Besevler-Ankara, Turkey.E-mail: elerman@ankara.edu.tr

\section{Keywords: alloying, magnetocaloric material, powder diffraction}

Nowadays, a number of families of alloys are being investigated in detail in order to find the optimum magnetocaloric material to utilize in magnetic refrigeration. Historically, the first one of these is the $\mathrm{Gd}_{5}\left(\mathrm{Si}_{\mathrm{x}} \mathrm{Ge}_{1-\mathrm{x}}\right)_{4}$ ternary compounds family. Great deal of research has been done to clarify the structural, magnetic and electronic aspects of this highly interesting family. Alloying is one of the most effective processes for altering and/or tuning the major magnetic characteristic of material [1-4]. The effect of alloying the parent $\mathrm{Gd}_{5} \mathrm{Si}_{2} \mathrm{Ge}_{2}$ (GSG) compound with $3 \mathrm{~d}(\mathrm{Co}$ and $\mathrm{Mn})$ and $\mathrm{p}(\mathrm{Ga}$ and $\mathrm{B})$ elements have been investigated. The alloying mechanism causes simultaneous substitution of the nonmagnetic $\mathrm{Si}$ and $\mathrm{Ge}$ atoms from the $(\mathrm{Si}+\mathrm{Ge})$ sublattice in equal amounts. X-ray powder diffraction, magnetization vs temperature and magnetization vs applied magnetic field at constant temperature data were collected. Curie temperatures were determined from $\mathrm{M}(\mathrm{T})$ measurements and the magnetocaloric characterization was made by plotting the magnetic entropy change values against temperature from $\mathrm{M}(\mathrm{H})$ measurements. The magnetic characteristics of the parent compound were significantly modified by alloying with Co.

[1] Pecharsky V.K., Gschneidner Jr. K.A., Phys. Rev. Lett., 1997, 78, 4494.

[2] Pecharsky V.K., Gschneidner Jr. K.A, J. Magn. Magn. Mat. 1997, 167, L179.

[3] Pecharsky V.K., Samolyuk G.D., Antropov V.P., Pecharsky A.O., Gschneidner Jr. K.A., J. Solid State Chem., 2003, 171, 57.

[4] Choe W., Pecharsky V.K., Pecharsky A.O., Gschneidner Jr. K.A., Young V.G., Miller G.J., Phys. Rev. Lett., 2000, 84, 4617.

\section{m30.p06}

\section{Structural Investigation of Amorphous Li2O-WO3-B203 Glass}

\author{
Karimat El-Sayed $^{\mathrm{a}}$, Ali Aboushama ${ }^{\mathrm{a}}$ and Hamdy Doweidar ${ }^{\mathrm{b}}$ \\ ${ }^{a}$ Physics Department, Faculty of Science,Ain-Shams University, Cairo \\ 11566, Egypt, ${ }^{b}$ Physics Department, Faculty of Science, Mansoura University, \\ Mansoura, Egypt
}

\section{Keywords: tangestate glasses, amorphous compounds, structural investigation}

The X-Ray scattering technique has been applied to study a series of amorphous tangestate $\left(\mathrm{Li}_{2} \mathrm{O}-\mathrm{WO}_{3}-\mathrm{B}_{2} \mathrm{O}_{3}\right)$ glasses. The prepared samples had an equal molar ratio of $\mathrm{Li}_{2} \mathrm{O}$ and $\mathrm{WO}_{3}$, in the range (17.5-33.75) mole\%. This corresponds to a varied ratio in $\mathrm{B}_{2} \mathrm{O}_{3}$. The data were collected by Mo X-ray scattered radiation of $(=0.709 \AA)$. The scattered data had been Fourier transformed to the real space. The structural information obtained from the radial distribution function (RDF) analysis; in the short (SRO) and medium range order (MRO) are significant and in good relation with some of the measured physical properties. The result showed a wide change in the bond lengths of the (B-O) first nearest neighbor distance. This Change in the Bond lengths were correlated with the wide range of change of $\mathrm{B}_{2} \mathrm{O}_{3}$ mole $\%$ (32.5-65). The basic structural unit was in the BO3 form of an extended distance (1.30-1.499) $\AA$. The second nearest neighbor of $\mathrm{W}-\mathrm{O}$ bonds were arranged in form of distorted $\mathrm{WO}_{6}$ octahedra of a different bond lengths (1.71$2.149) \AA$. Accordingly the $\mathrm{O}-\mathrm{W}-\mathrm{O}$ connected units inside the amorphous matrix largely deform the SRO region. Both of B-B and $\mathrm{O}-\mathrm{O}$ correlations are of smaller weights and are observed as shoulders within a main representative peak. The MRO is observed in the form of super-structural units (Boroxol Groups $\mathrm{B}_{3} \mathrm{O}_{6}$ ) of connected $\mathrm{B}-\mathrm{O}$ units of non-bridging oxygen (NBO) and bridged ones $(\mathrm{BO})$ respectively. The $\mathrm{NBO}$ were detected in the range ( $3.099-3.25) \AA$ and the other $\mathrm{BO}$ were observed in the range (3.489-3.788) $\AA$. The role of $\mathrm{Li}_{2} \mathrm{O}$ as a modifier in the network was able to convert cyclically $\mathrm{BO}_{3}-\mathrm{BO}_{4}-\mathrm{BO}_{3}$ forms of both symmetric and anti-symmetric correlated distances inside the MRO and also SRO, this is due mainly to the free circulation of the $\mathrm{Li}$ ions in the amorphous lattice. The degree of network disorder in the amorphous matrix decreased largely with the increase of the molecular percentages of $\mathrm{B}_{2} \mathrm{O}_{3}(50-65)$ mole $\%$. The result also showed that the basic amorphous structural units do not exist in the low $\mathrm{B}_{2} \mathrm{O}_{3}(5-30)$ mole \%. The molecular densities and the electrical conductivity were measured and were correlated with the structural information obtained from this series of amorphous glasses. 